\title{
ESTADO DO CONHECIMENTO: EXPERIÊNCIAS DE APRENDIZAGEM E DE ENSINO DE ESTATÍSTICA
}

\section{STATE OF KNOWLEDGE: EXPERIENCES OF LEARNING AND TEACHING OF STATISTICS}

\author{
Camila Rubira Silva \\ Universidade Federal do Rio Grande - FURG \\ camilarubira@hotmail.com \\ Débora Pereira Laurino \\ Universidade Federal do Rio Grande - FURG \\ deboraplaurino@gmail.com
}

\section{Resumo}

Neste artigo mapeamos e discutimos a produção científica sobre as experiências de aprendizagem e de ensino de Estatística, por meio do Estado do Conhecimento de artigos publicados em periódicos da área da Educação Matemática. O corpus foi composto por 31 artigos indexados entre jan./2010 e out./2020 em 24 periódicos eletrônicos brasileiros da área da Educação Matemática, classificados em estratos de qualidade A1, A2, B1 e B2. No tratamento dos dados adotamos os conhecimentos da Estatística Descritiva e a nuvem de palavras para apresentar informações sobre a quantificação, periodização, origem e abordagem dos estudos, bem como as técnicas de Análise de Conteúdo (BARDIN, 1977) para a proposição de categorias temáticas. Assim, emergiram cinco categorias que versam sobre as experiências de aprendizagem e de ensino de Estatística voltadas a: ludicidade na Educação Infantil e Anos Iniciais; temas transversais nos Anos Finais; sequências de ensino e jogos no Ensino Médio; tecnologias digitais na Educação Superior e, na formação de professores a participação em projetos e grupos de estudos. Consideramos que esta investigação possa contribuir para (re)pensarmos as experiências que tem sido (re)produzidas na aprendizagem e no ensino de Estatística, visando a promoção de práticas pedagógicas que sejam mais significativas para estudantes e professores.

Palavras-chave: Educação Estatística; Experiência; Estado do Conhecimento; Periódicos.

\begin{abstract}
In this paper we map and discuss the scientific production on the experiences of learning and teaching Statistics, through the State of Knowledge of articles published in journals in area of Mathematics Education. The corpus was composed of 31 articles indexed between jan./2010 and oct./2020 in 24 brazilian electronic journals the area of Mathematics Education that are classified in quality strata A1, A2, B1 and B2. In the treatment of the data, we adopted the knowledge of Descriptive Statistics and the word cloud to present information about the quantification,
\end{abstract}


periodization, origin and approach of the studies, as well as the techniques of Content Analysis (BARDIN, 1977) for proposing categories thematic. Thus, five categories emerged that deal with the experiences of learning and teaching Statistics aimed at: playfulness in Early Childhood Education and Early Years; transversal themes in the Final Years; teaching sequences and games in High School; digital technologies in Higher Education and the teacher training participation in projects and study groups. We believe that this investigation can contribute to (re)think the experiences that have been (re)produced in learning and teaching Statistics, aiming at the promotion of pedagogical practices that are more significant for students and teachers.

Keywords: Statistical Education; Experience; State of Knowledge; Periodicals.

\section{INTRODUÇÃO}

Nos últimos anos estudos na área da Educação Estatística tem se intensificado, especialmente, conforme Silva, Curi e Schimiguel (2017) pelo aumento da produção científica do GT12 (Grupo de Trabalho sobre Ensino de Probabilidade e Estatística) da Sociedade Brasileira de Educação Matemática (SBEM). Segundo Samá (2019) a partir da criação desse GT no ano de 2000, a produção científica em Educação Estatística tem despontado, contribuindo com reflexões sobre o ensinar e o aprender Estatística no que concerne tanto os aspectos cognitivos e afetivos, quanto epistemológicos dos conceitos estatísticos e da promoção de estratégias didáticas, visando o Letramento Estatístico.

Nesse sentido, estudos com abordagem em problematizações sobre o ensinar e o aprender Estatística, a partir das experiências formativas vivenciadas e partilhadas por estudantes e professores pode favorecer não só a reflexão sobre as implicações dessas experiências nas continuidades e rupturas dos processos formativos, mas também instigar a (re)significação das mesmas. Para Larrosa (2019) uma experiência é o que nos toca e ao nos tocar nos deixa marcas e vestígios. Tardif (2019) acrescenta que as marcas do processo formativo são transformadas e carregadas pelo professor sob a forma de crenças, sendo reativadas na prática docente, principalmente, para solucionar os problemas profissionais.

Dessa forma, "se o professor não passa por experiências significativas numa determinada área do conhecimento, durante sua escolarização e formação inicial, é provável que se sinta inseguro para incorporá-la em sua prática profissional" (COSTA; NACARATO, 2011, p. 377). Assim, defendemos a necessidade dos estudantes e professores vivenciarem experiências de aprendizagem e de ensino de Estatística que sejam significativas para si e para os outros sujeitos com quem se relacionam. 
Face ao exposto, objetivamos mapear e discutir a produção científica sobre as experiências de aprendizagem e de ensino de Estatística, por meio do Estado do Conhecimento de artigos publicados entre jan./2010 e out./2020 em periódicos eletrônicos brasileiros indexados na área da Educação Matemática. Conforme, Barbosa, Santos e Lopes (2019) pesquisas que tem como enfoque a sistematização da produção científica por meio do mapeamento bibliográfico em acervos de teses, dissertações, periódicos, anais de eventos regionais, nacionais, e internacionais, podem contribuir para disseminação do conhecimento apontando caminhos, tendências e lacunas nas opções dos pesquisadores.

\section{DELINEAMENTO METODOLÓGICO}

O presente artigo consiste em uma pesquisa qualitativa, com delineamento no Estado do Conhecimento, o qual corresponde "“...] identificação, registro, categorização que levem à reflexão e síntese sobre a produção científica de uma determinada área, em um determinado espaço de tempo" (MOROSINI, 2015, p. 102).

Nesse âmbito, tanto o Estado do conhecimento, quanto o Estado da Arte caracterizam-se como estudos de cunho bibliográfico invariante e descritivo, que compartilham "o desafio de mapear e de discutir uma certa produção acadêmica em diferentes campos do conhecimento, tentando responder que aspectos e dimensões vêm sendo destacados e privilegiados em diferentes épocas e lugares [...]" (FERREIRA, 2002, p. 259). Entretanto, diferenciam-se com relação a abrangência dos estudos, ao passo que o Estado da Arte abarca toda uma área do conhecimento nos diferentes aspectos que geram a produção, o Estado do Conhecimento aborda apenas um setor de publicações sobre um determinado tema (ROMANOWSKI; ENS, 2006). Para as autoras esses estudos são justificados por fornecerem uma visão geral do que vem sendo produzido em uma determinada área, possibilitando aos interessados perceberem a evolução, as características, o foco e as brechas existentes nas pesquisas (ROMANOWSKI; ENS, 2006).

Para problematizar o objeto desta pesquisa abordamos como fonte primordial os periódicos brasileiros de acesso digital indexados na área da Educação Matemática. De acordo com Gil (2002, p. 66), os periódicos têm se constituído como um importante meio para a comunicação científica, pois [...] "graças a eles é que vem se tornando possível a comunicação formal dos resultados de pesquisas originais e a manutenção do padrão de 
qualidade na investigação científica". A fonte foi composta por 24 periódicos eletrônicos brasileiros (Quadro 1) indexados na área da Educação Matemática que estão classificados em estratos de qualidade A1, A2, B1 e B2 no quadriênio de 2013-2016, segundo a avaliação do sistema Web-Qualis da Coordenação de Aperfeiçoamento de Pessoal de Nível Superior (CAPES). Desses, encontramos um periódico classificado em A1, 12 A2, cinco em B1, seis em B2.

\begin{tabular}{|c|c|c|c|}
\multicolumn{2}{|c}{ Quadro 1 - Periódicos eletrônicos utilizados como fonte da pesquisa } \\
\hline PERIÓDICO & QUALIS & PERIÓDICO & QUALIS \\
\hline $\begin{array}{c}\text { BOLEMA - Boletim de Educação } \\
\text { Matemática }\end{array}$ & A1 & ZETETIKE & A2 \\
\hline $\begin{array}{c}\text { ACTA SCIENTIAE - Revista de } \\
\text { Ensino de Ciências e Matemática }\end{array}$ & A2 & $\begin{array}{c}\text { BoEM - Boletim Online de } \\
\text { Educação Matemática }\end{array}$ & B1 \\
\hline Alexandria & A2 & $\begin{array}{c}\text { Perspectivas da Educação } \\
\text { Matemática }\end{array}$ & B1 \\
\hline $\begin{array}{c}\text { AMAZÔNIA - Revista de } \\
\text { Educação em Ciências e } \\
\text { Matemáticas }\end{array}$ & A2 & $\begin{array}{c}\text { Em Teia - Revista de Educação } \\
\text { Matemática e Tecnológica } \\
\text { Iberoamericana }\end{array}$ & B1 \\
\hline $\begin{array}{c}\text { EMR - Educação Matemática em } \\
\text { Revista - SP }\end{array}$ & A2 & $\begin{array}{c}\text { RBHM - Revista Brasileira de } \\
\text { História da Matemática }\end{array}$ & B1 \\
\hline $\begin{array}{c}\text { EMR - Educação Matemática em } \\
\text { Revista - RS }\end{array}$ & A2 & $\begin{array}{c}\text { RPEM - Revista Paranaense de } \\
\text { Educação Matemática }\end{array}$ & B1 \\
\hline $\begin{array}{c}\text { EMP - Educação Matemática } \\
\text { Pesquisa }\end{array}$ & A2 & $\begin{array}{c}\text { Caminhos da Educação Matemática } \\
\text { em Revista }\end{array}$ & B2 \\
\hline $\begin{array}{c}\text { JIEEM - Jornal Internacional de } \\
\text { Estudos em Educação Matemática }\end{array}$ & A2 & $\begin{array}{c}\text { Hipátia - Revista Brasileira De } \\
\text { História, Educação e Matemática }\end{array}$ & B2 \\
\hline $\begin{array}{c}\text { REnCiMa - Revista de Ensino de } \\
\text { Ciências e Matemática }\end{array}$ & A2 & $\begin{array}{c}\text { Rematec - Revista de Matemática, } \\
\text { Ensino e Cultura }\end{array}$ & B2 \\
\hline $\begin{array}{c}\text { REVEMAT: Revista Eletrônica de } \\
\text { Educação Matemática }\end{array}$ & A2 & $\begin{array}{c}\text { RPM - Revista do Professor de } \\
\text { Matemática }\end{array}$ & B2 \\
\hline $\begin{array}{c}\text { RECM - Revista de Educação, } \\
\text { Ciências e Matemática }\end{array}$ & A2 & $\begin{array}{c}\text { RIPEM - Revista Internacional e } \\
\text { Pesquisa em Educação Matemática }\end{array}$ & B2 \\
\hline VIDYA & $\begin{array}{c}\text { ReviSeM - Revista Sergipana de } \\
\text { Matemática e Educação Matemática }\end{array}$ & B2 \\
\hline
\end{tabular}

Fonte: Elaborado pelas autoras, 2020.

$\mathrm{Na}$ constituição do corpus de análise incialmente utilizamos os descritores "Experiência(s)" e "Estatística", bem como a busca avançada da periodicidade compreendida entre jan./2010 e out./2020, recuperando 1698 artigos. A opção por este recorte temporal está fundamentada na intenção de filtrarmos um maior número de estudos atualizados e relevantes na área da Educação Estatística, considerando tanto o período dos últimos cincos (2015-2020), quanto a primeira metade desta década (2010-2014), momento em que foram publicadas algumas edições especiais de revistas e eventos científicos em 
âmbito nacional/internacional com potencial contribuição para o GT12 (SILVA, 2015) ${ }^{1}$. Posteriormente, através do cruzamento entre os descritores "Experiência(s)" e "Estatística" e da leitura flutuante dos títulos e dos resumos com referência aos critérios de inclusão e exclusão, selecionamos 31 artigos científicos que compõe o nosso corpus de análise. Esta leitura se insere na etapa de Pré Análise da Análise de Conteúdo, com o objetivo estabelecer um primeiro contato do pesquisador com os materiais a serem analisados (BARDIN, 1977).

Assim, incluímos todos os artigos que atenderam aos seguintes critérios: 1) abordar a temática experiência na área da Educação Estatística; 2) mencionar experiência(s) de aprendizagem e de ensino de Estatística em diferentes níveis de escolarização da Educação Básica até a Superior, bem como em situações do cotidiano. Do mesmo modo, descartamos os artigos que se enquadraram nos critérios: 1) abordar a temática experiência em outras áreas do conhecimento, exceto Educação Estatística; 2) mencionar o termo experiência de forma isolada na biografia dos autores, citações e/ou referências.

Com o corpus de análise selecionado passamos a construção da bibliografia anotada e sistematizada, na qual constroem-se inicialmente tabelas identificando os dados extraídos nas fontes de produção científica (MOROSINI; FERNANDES, 2014). Dessa forma, realizamos a codificação do material, etapa compreendida na Exploração do Material da Análise de Conteúdo, na qual o pesquisador transforma sistematicamente os dados brutos em unidades de registro, descrevendo de forma exata as características do conteúdo (BARDIN, 1977). Para tanto, incialmente realizamos a leitura dos artigos na integra identificando e destacando as informações pertinentes ao objetivo de estudo. Posteriormente, organizamos estas informações, em planilha eletrônica, extraindo os seguintes dados: 1) periódico eletrônico; 2) título do artigo; 3) descritores; 4) ano de publicação; 5) vínculo institucional do(s) autor(es); 6) estado/região; 7) objetivo; 8) procedimento metodológico; 9) resultados; 10) conclusões.

\footnotetext{
${ }^{1}$ Com relação a produção científica da área da Educação Estatística, em especial, nos anos de 2010 a 2014 Silva (2015) destaca em âmbito nacional a edição temática da revista BOLEMA em 2011 e do Encontro Nacional de Educação Matemática (ENEM) nos anos de 2010 e 2013, assim como, em âmbito internacional as edições da revista Statistics Education Research Journal (SERJ) e Revista de Investigação em Educação Matemática (Quadrante) ambas em 2014 e das áreas temáticas em eventos como International Conference on Teaching Statistics (ICOTS) em 2010 e 2014, Conferência Interamericana de Educação Matemática (CIAEM) em 2011, Congresso Internacional de Educação Matemática (CIEM) nos anos de 2010 e 2013 e o Simpósio Internacional de Pesquisa em Educação Matemática (SIPEMAT) em 2012.
} 
No tratamento desses dados adotamos os conhecimentos da Estatística Descritiva para apresentar por meio de gráficos as informações sobre a quantidade de artigos recuperados por periódico eletrônico e ano de publicação. Também utilizamos a nuvem de palavras para identificar os descritores mencionados pelos autores para indexar os artigos nos periódicos. Além disso, realizamos uma descrição dos estados e das regiões do país onde estão situados os autores e/ou grupos de pesquisas que tem se dedicado a publicações sobre a temática investigada.

Com os demais dados - objetivo, procedimento metodológico, resultados e conclusões - efetuamos o processo de "proposição de possíveis categorias" (MOROSINI; FERNANDES, 2014, p. 157), por meio das técnicas de Análise de Conteúdo (BARDIN, 1977). Esta categorização compõe a etapa de Exploração do Material da Análise de Conteúdo, na qual o pesquisador opera na classificação dos dados por diferenciação e reagrupamento segundo critérios definidos (BARDIN, 1977). Assim, optamos por categorizar os estudos pelo critério semântico, criando categorias temáticas conforme o agrupamento das unidades de registro com referência aos temas que elas significavam. Dessa forma, classificamos os artigos diferenciando e reagrupando os dados segundo os tempos e os espaços de ocorrência das experiências e dos sujeitos que as vivenciaram.

\section{MAPEAMENTO E DISCUSSÃO DA PRODUÇÃO CIENTÍFICA SOBRE AS EXPERIÊNCIAS DE APRENDIZAGEM E DE ENSINO DE ESTATÍSTICA}

No mapeamento e na discussão da produção científica sobre as experiências de aprendizagem e de ensino de Estatística, verificamos que em $44 \%$ dos periódicos eletrônicos brasileiros que constituíram a fonte - ACTA SCIENTIAE, ALEXANDRIA, EMP, VIDYA, BoEM, RBHM, RPEM, HIPÁTIA, RPM, ReviSeM, ZETETIKE - não foram recuperados estudos que atendessem aos critérios inclusão.

Dentre os $56 \%$ dos periódicos (Gráfico 1) nos quais selecionamos 31 artigos destacase, em especial, a BOLEMA com a publicação de oito artigos sobre a temática investigada. Isso pode ser atribuído pelo fato da revista ter um alto nível de avaliação pelo sistema $\mathrm{Web}$ Qualis-CAPES, que lhe confere o extrato A1 para área de avaliação em Ensino, sendo um dos principais periódicos da área da Educação Matemática. 
Gráfico 1 - Periódicos eletrônicos utilizados como fonte da pesquisa

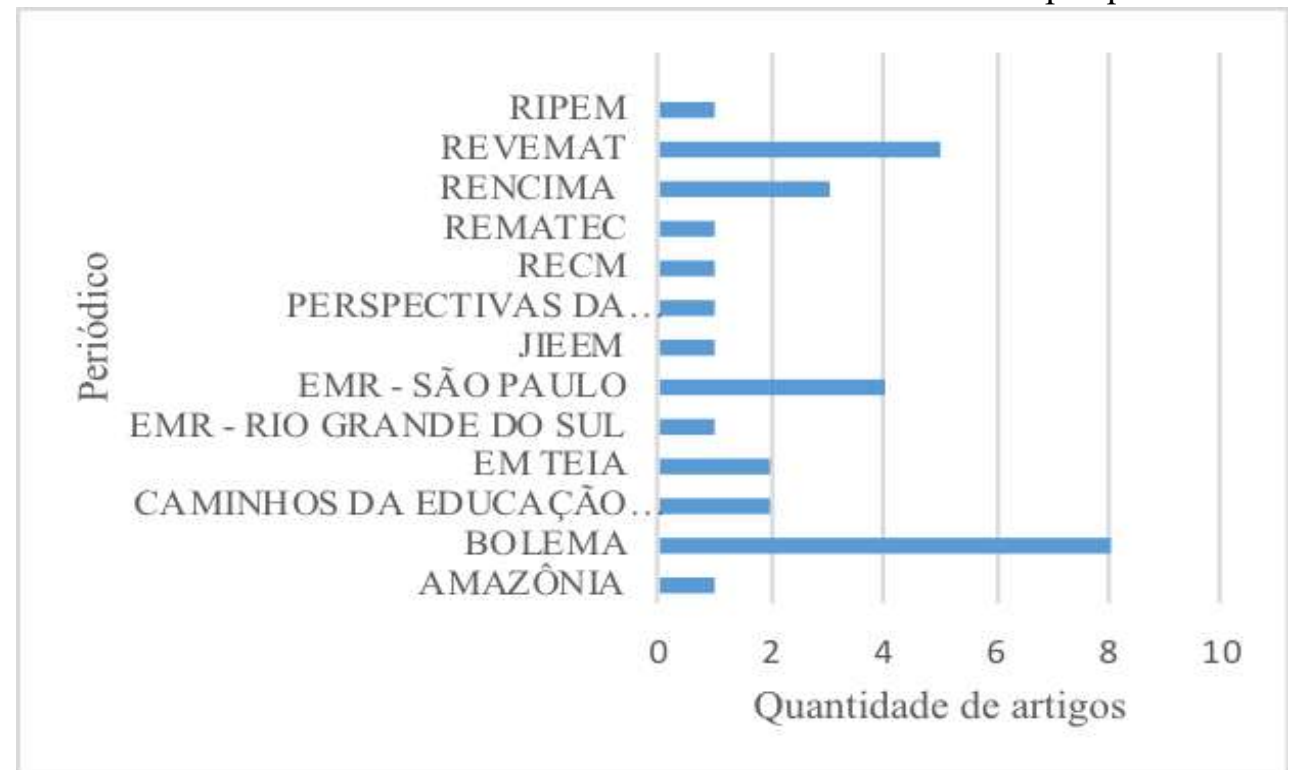

Fonte: Elaborado pelas autoras, 2020.

Com relação a periodicidade dos artigos entre a década de jan./2010 a out./2020 (Gráfico 2), evidenciamos um ápice de publicações nos anos de 2011 e 2019. Nesta investigação percebemos que algumas revistas científicas lançaram edições temáticas na área da Educação Estatística, como a BOLEMA em 2011 e a REVEMAT em 2019. Silva (2015), em especial, menciona a contribuição da revista BOLEMA no ano de 2011, com publicação de dois volumes com a edição temática da Educação Estatística, contemplando um total de 26 artigos, dentre os quais 16 foram produzidos por pesquisadores membros do GT12. Além dessas, tiveram também edições nas revistas Vidya e EMP em 2016 e REnCiMa em 2018 (SAMÁ, 2019). A parir de 2015 até o ano de 2019 notamos um crescimento de pesquisas sobre a temática investigada. O que demonstra uma preocupação da comunidade científica da área da Educação Estatística em problematizar e valorizar as experiências formativas como uma fonte de produção e mobilização de saberes. 
Gráfico 2 - Periodicidade de artigos selecionado

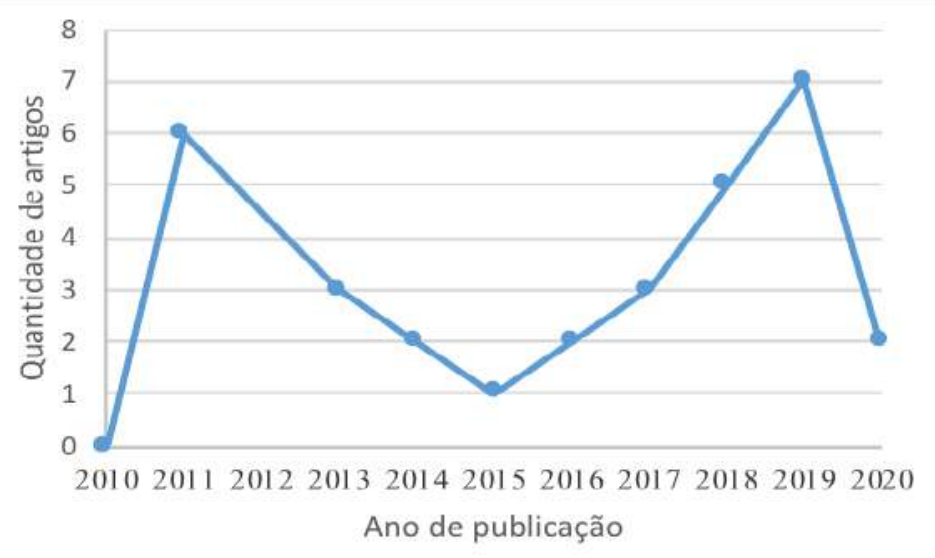

Fonte: Elaborado pelas autoras, 2020.

Na distribuição dos artigos selecionados por região do país, consideramos a origem das pesquisas com referência aos dados do primeiro autor. Assim, identificamos pesquisas provenientes das seguintes regiões: 65\% Sudeste - São Paulo, Minas Gerais, Rio de Janeiro e Espírito Santo; 23\% Sul - Rio Grande do Sul e Paraná; 6\% Centro-Oeste - Mato Grosso do Sul e 6\% Nordeste - Bahia e Paraíba. Não encontramos pesquisas originadas na Região Norte do Brasil.

Barbosa, Santos e Lopes (2019) ao mapearem os trabalhos com abordagem na área de Educação Estatística, apresentados nos anais do XII Encontro Nacional de Educação Matemática realizado no ano de 2016, evidenciaram uma maior contribuição de pesquisas provenientes da Região Sudeste do país. Silva, Curi e Schimiguel (2017) ao investigarem a produção científica sobre Educação Estatística divulgada na BOLEMA entre o período de 2006-2015, observaram a prevalência publicações com origem em Instituições de Ensino Superior no estado de São Paulo - Universidade Bandeirante (UNIBAN); Universidade Cruzeiro do Sul (UNICSUL), Universidade Estadual Paulista (UNESP), Universidade São Francisco (USF), Pontifícia Universidade Católica (PUC) e, Universidade Estadual de Campinas (UNICAMP).

Com base nisso percebemos que a Região Sudeste, principalmente, o estado de São Paulo tem se destacado na produção científica na área da Educação Estatística. Tal fato pode estar a associado ao número significativo de instituições de ensino e de grupos de pesquisas provenientes deste estado, uma vez que nesta investigação identificamos estudos com origem nas seguintes instituições: UNESP; USF; UNICAMP; UNICSUL; PUC 
CAMPINAS; Instituto Federal de São Paulo (IFSP); Universidade Metropolitana de Santos (UNIMES) e; Universidade Presbiteriana Mackenzie.

Na elaboração da nuvem de palavras (Figura 1) a partir dos descritores mencionados nos artigos para indicar as temáticas e métodos abordados nos estudos, bem como indexálos nas plataformas das revistas eletrônicas destacaram-se as palavras com referência a própria área de investigação como: Educação Estatística, Ensino de Estatística, Educação Matemática. Além dessas, palavras que remetem aos conhecimentos estatísticos: Estocástica, Pensamento Estatístico, Literacia Estatística, Letramento Estatístico, Tratamento da Informação, Aprendizagem em Estatística e Probabilidade.

Figura 1 - Nuvem de palavras descritores artigos selecionados

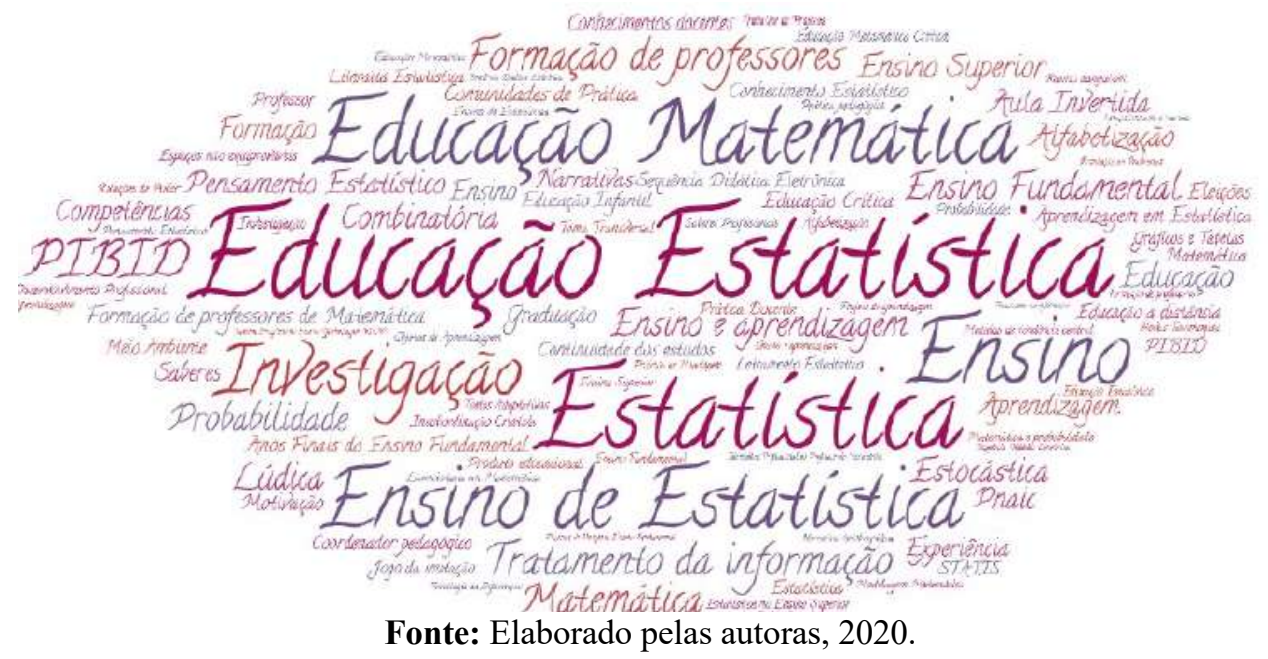

Vale aqui diferenciarmos alguns desses termos comumente utilizados na área da Educação Estatística, mas que tem significados distintos. Segundo Costa e Nacarato (2011) a 'estocástica' tem sido empregada em vários países do mundo com referência a integração entre a Estatística e a Probabilidade. Por sua vez, o termo 'Tratamento da Informação', faz referência ao bloco de conteúdos estatísticos apresentado nos Parâmetros Curriculares Nacionais da Educação - PCN (SANTANA et al., 2017).

O termo 'Pensamento Estatístico' diz respeito a capacidade do sujeito identificar e analisar uma situação concreta escolhendo as ferramentas estatísticas mais adequadas para sua descrição e interpretação (MELO; GROENWALD, 2018). Com base nisso, Silva e Silva (2019) descrevem que o 'Letramento Estatístico' está relacionado ao pensamento estatístico, o qual possibilita ao sujeito assumir o processo de obtenção, tratamento e análise crítica dos dados. Já a 'Literacia Estatística' é compreendida como a competência em que o sujeito 
adquire um conjunto de conhecimentos, convicções e habilidades para lidar de maneira eficaz com situações envolvendo dados que surgem na vida (PERIN; WODEWOTZKI, 2019).

Na nuvem de palavras também observamos termos com referência a temática de investigação - formação de professores, conhecimentos docentes, prática docente e conhecimento didático - assim como, palavras que indicam os lócus das investigações de acordo com níveis de ensino e/ou projetos - Ensino Superior, Graduação, Educação Infantil, Ensino Fundamental, Programa Institucional de Bolsas de Iniciação à Docência (Pibid) e Pacto Nacional pela Alfabetização na Idade Certa (PNAIC). Algumas palavras versaram sobre as metodologias de ensino: Sequência Didática Eletrônica, Lúdica, Aula Invertida, Investigação, Comunidades de Prática e Educação Crítica.

Nesse sentido, percebemos a importância da produção e da divulgação de pesquisas sobre a formação de professores no que concerne suas experiências, saberes e práticas de ensino de Estatística. Corroborando, Oliveira Júnior, Anjos e Silva (2019) defendem a necessidade de investimento na formação de professores, de modo a contribuir para que os professores sejam receptivos a novas metodologias fornecendo condições para que a escola assuma diferentes realidades.

No processo de categorização dos artigos, emergiram cinco categorias que indicam as experiências de aprendizagem e de ensino de Estatística provenientes: $52 \%$ da formação profissional para a docência; 19\% dos Anos Finais do Ensino Fundamental; 13\% da Educação Superior; 10\% do Ensino Médio e 6\% da Educação Infantil e dos Anos Iniciais o Ensino Fundamental. Esta categorização nos possibilita perceber que as experiências e os saberes dos professores provêm de espaços e tempos antes mesmo do ingresso na carreira docente propriamente dita (TARDIF, 2019).

\section{Experiências provenientes da formação profissional para a docência}

Costa e Nacarato (2011) investigaram como professores de Matemática de escolas públicas/privadas na região de Jundiaí/SP perceberam a inserção da estocástica na sua formação e prática profissional, e como formadores desses professores percebiam a inserção da estocástica na formação dos mesmos. Os resultados evidenciaram que a formação inicial 
e continuada não tem contribuído para um repertório de saberes que os possibilite atuar frente ao desafio de formar o pensamento estocástico dos estudantes.

Oliveira Júnior (2011) por meio da investigação sobre o uso de tecnologias e de práticas docentes de 334 professores que ministram disciplinas de Estatística em cursos das áreas de Exatas, Humanas e Saúde de instituições públicas e privadas da Educação Superior, destacou que a internet é utilizada como apoio à prática pedagógica desses professores e que os mesmos reforçam a importância da Estatística às diversas profissões.

Pamplona e Carvalho (2011) refletiram sobre a existência de relações de poder em comunidades envolvidas na formação Estatística do professor de Matemática. Concluíram que existe duas comunidades dedicadas à formação Estatística do professor de Matemática, uma oriunda da Educação e outra da Matemática, sendo necessário a integração entre as mesmas por parte dos sujeitos que se dedicam a produzir conhecimento na área.

Campos et al. (2011) investigaram três competências definidas e estudadas no âmbito da Educação Estatística (literacia, pensamento e raciocínio estatístico). Compreenderam, a partir de um o projeto de ensino de Estatística, que a Modelagem Matemática pode ser uma possibilidade de integração entre a Educação Crítica e a Educação Estatística.

Costa e Pamplona (2011) apresentaram reflexões e ações enfrentadas no desafio de (re)construir a identidade profissional do futuro educador matemático, na busca por tornalo também um educador estatístico. Neste estudo as autoras enfatizaram a necessidade de intensificar as relações entre Matemática, Estatística, Pedagogia, Ética e Formação Profissional do licenciando em Matemática.

Lopes (2013) problematizou o desenvolvimento teórico e metodológico da disciplina de Estatística no curso de formação inicial do futuro professor de Matemática a partir da experiência de estágio na referida disciplina. Os resultados indicaram a importância da interação entre os futuros professores e os professores em serviço durante as aulas regulares da disciplina para o desenvolvimento do pensamento estatístico e para a percepção sobre o trabalho a ser desenvolvido com seus futuros estudantes.

Oliveira Júnior e Fernandes (2013) descreveram uma atividade que teve como objetivo possibilitar aos acadêmicos e professores do PIBID/Matemática, a prática da Estatística através de atividades de ensino utilizando projetos e a tecnologia da informação. 
Com isso, observaram que a experiência do trabalho em grupo aumentou o interesse pelo assunto abordado, bem como mobilizou atitudes para que o conhecimento tivesse significado dentro do contexto do cotidiano.

Amâncio, Vianna e Rocha (2013) identificaram os conhecimentos de conteúdo, curricular e pedagógico, mobilizados por licenciandos em Matemática que aplicaram uma sequência didática sobre Probabilidade no âmbito do PIBID. Nesta investigação apontaram que os acadêmicos desenvolveram tanto a iniciação de um hábito investigativo e reflexivo sobre prática buscando tornar a aula mais atrativa e facilitar a construção do conceito, quanto mobilizaram o conhecimento de conteúdo e pedagógico.

Lopes (2014) discutiu a potencialidade das narrativas para o desenvolvimento profissional de duas professoras que ensinam Matemática no Ensino Fundamental e estão inseridas em um grupo de trabalho colaborativo que tem por objetivo viabilizar a superação do desafio de implementar a Educação Estatística em suas aulas. Com isso, enfatizou que a construção de narrativas possibilitou as professoras reconstruir as suas próprias experiências de ensino e de aprendizagem e os seus percursos de formação permitindo um aprimoramento didático a partir da reflexão sobre a teoria e a prática.

Estevam e Cyrino (2016) problematizaram o desenvolvimento profissional de professores de Matemática no contexto da Educação Estatística, por meio da revisão de pesquisas nacionais/internacionais e excertos da experiência de uma Comunidade de Prática de professores. Como fatores limitantes ao desenvolvimento profissional adequado a Educação Estatística foi apontado: a falta de políticas que oportunizem espaços de formação visando a superação do ensino tecnicistas; a escassez de recursos disponíveis; o uso exclusivo do livro didático; a insuficiência de Conhecimento Pedagógico de Estatística.

Oliveira Júnior, Anjos e Silva (2017) buscaram possibilitar aos acadêmicos e professores supervisores bolsistas do PIBID/Matemática de uma Universidade Federal de Minas Gerais, a prática da Estatística por meio de atividades de ensino utilizando projetos. Os resultados indicaram que as atividades de organização de pesquisa, coleta, tabulação, interpretação e análise dos dados despertaram o espírito investigativo dos acadêmicos.

Santana et al. (2017) refletiram sobre o papel dos coordenadores pedagógicos no processo de formação continuada de professores que ensinam Matemática nos Anos Iniciais do Ensino Fundamental. Destacaram que os coordenadores puderam adquirir 
conhecimentos sobre o seu papel e sobre os conhecimentos matemáticos relativos ao bloco de conteúdo Tratamento da Informação em um processo de colaboração, contribuindo para que os professores aperfeiçoassem seus saberes e práticas relativas a esse bloco.

Barbosa (2018) investigou as práticas pedagógicas voltadas ao ensino e a aprendizagem da Estatística na formação continuada de professores, oferecida pelo Pnaic. A partir disso verificou que as alfabetizadoras demostraram a percepção sobre: a importância da pesquisa como eixo estruturador de ações pedagógicas e do conteúdo de Estatística; a necessidade de oportunizar aos estudantes a aprendizagem de conhecimentos estatísticos por meio da experiência de procedimentos de pesquisas e da interpretação crítica de dados; e a possibilidade da Estatística ser trabalhada com questões simples.

Figueiredo (2019) analisou como a experiência de aplicação de sequências de ensino que envolvem conceitos de Estatística podem contribuir na formação docente de estudantes de Licenciatura em Pedagogia. Com isso, constatou que a experiência possibilitou aos acadêmicos mobilizarem conhecimentos relativos à Estatística na Educação Básica contribuindo para a aproximação entre a teoria e a prática.

Silva (2019) discutiu a abordagem do uso de material concreto manipulável, Caixa Estatística, como um recurso didático para otimizar o estudo e o aprendizado de Estatística. $\mathrm{O}$ autor considera que a experiência de manipulação deste material nos cursos de formação de professores se constituí em uma excelente maneira de contribuir para a formação prática de futuros professores de Matemática, frisando a necessidade do planejamento, do conhecimento do material e da definição dos objetivos de ensino.

Silva e Porciúncula (2020) identificaram os atos de Insubordinação Criativa revelados nas experiências de aprendizagem e de ensino de Estatística narradas pela primeira autora. Revelaram cinco atos: deixar que algo the passe por meio da aprendizagem espontânea na infância; colocar-se na reflexividade de experiências pouco significativas da Educação Básica; assumir a sua auto/transformação buscando experiências mais significativas em projetos e grupos de estudos na Educação Superior; (re)significar as suas experiências na atuação em projetos e ministrando aulas; deixar vestígios e provocar efeitos pesquisando na área da Educação Estatística. 


\section{Experiências provenientes dos Anos Finais do Ensino Fundamental}

Melo e Groenwald (2014) apresentaram a implementação de uma sequência didática eletrônica com conceitos estatísticos para o $9^{\circ}$ Ano do Ensino Fundamental, articulados com o tema transversal meio ambiente. Nos resultados destacaram que a experiência da sequência didática proporcionou aos estudantes a revisão e o aprofundamento dos conceitos estatísticos previamente estudados em aula, assim como, favoreceu um ambiente de cooperação e de construção do conhecimento entre os mesmos.

Melo e Groenwald (2015) apresentaram o processo de desenvolvimento de um banco de questões que compõe os testes adaptativos de uma sequência didática eletrônica que integra conceitos estatísticos com o tema transversal meio ambiente, elaborada para os Anos Finais do Ensino Fundamental. Neste estudo, constataram que o uso das Tecnologias da Informação e Comunicação como recurso didático possibilitou a professora um acompanhamento mais detalhado do desempenho dos estudantes, identificando e trabalhando as dificuldades individuais em relação aos conceitos estatísticos.

Jürgensen (2017) relatou uma experiência de projeto de investigação Estatística realizada com estudantes do $9^{\circ}$ Ano do Ensino Fundamental, em que os conceitos estatísticos foram articulados com o tema 'A violência e o papel da mulher na sociedade'. $\mathrm{O}$ autor concluiu que proporcionar o desenvolvimento da autonomia por meio da escolha de temas e da decisão sobre as etapas de execução da investigação é fundamental para que os estudantes desenvolvam habilidades que serão usadas durante toda a vida.

Scarlassari, Socha e Lopes (2018) narraram a experiência de atividades com enfoque na investigação Estatística, em que buscaram propiciar aos estudantes dos Anos Finais do Ensino Fundamental um olhar crítico em relação aos seus hábitos alimentares. Assim, evidenciaram que o processo investigativo oportunizou tanto a apropriação de saberes estatísticos, quanto aquisição de conhecimentos voltados ao cuidado alimentar.

Conceição et al. (2019) refletiram acerca de uma experiência com estudantes do $9^{\circ}$ Ano de uma escola pública do Espírito Santo, na qual foi proporcionado o ensino de Estatística de forma articulada ao tema transversal nutrição. Com essa pesquisa, foi observado que a experiência favoreceu além da aprendizagem dos estudantes em relação à Estatística, o pensamento crítico acerca da sua alimentação. 
Melo e Groenwald (2018) investigaram como a articulação da estratégia metodológica de projetos de pesquisa com a implementação de uma sequência didática eletrônica contendo os conceitos de Estatística contribuiu para a formação do pensamento estatístico em estudantes do $9^{\circ}$ Ano do Ensino Fundamental, que não tiveram acesso a esse estudo na escolarização anterior. Concluíram que a implementação oportunizou tanto o estudo dos conceitos estatísticos quanto a compreensão de aspectos conceituais, procedimentais e atitudinais desejáveis ao desenvolvimento da Literacia Estatística.

\section{Experiências provenientes da Educação Superior}

Souza Junior e Campos (2011) pesquisaram como as experiências com projetos voltados a Educação Estatística poderiam contribuir para o desenvolvimento acadêmico e profissional dos estudantes participantes. Concluíram que a articulação entre o conhecimento estatístico e a metodologia de projetos, pode contribuir para constituição de um curso de Estatística que priorize a formação de um cidadão crítico através da construção de conhecimentos que refletirão em sua vida pessoal e profissional.

Leal Junior e Onuchic (2018) buscaram perceber como estudantes de graduação em cursos de tecnologia reagem ao estarem imbricados na produção de seus conhecimentos estatísticos através da Resolução de Problemas contextualizados com experiências do seu cotidiano. Perceberam que a prática de Resolução de Problemas pode contribuir para novas perspectivas de ensino e de aprendizagem de Estatística, visando a construção de conceitos voltados a experiência dos sujeitos como um modo de compreensão do mundo onde vivem.

Bueno, Viali e Müller (2019) relataram a experiência da introdução de tecnologias no estudo da definição clássica de Probabilidade, através da exploração de um objeto de aprendizagem denominado 'Probabilidades' em cursos de Administração de Empresas e Ciências Contábeis de uma Universidade do Rio Grande do Sul. Com isso, apontaram que a exploração das tecnologias e do laboratório de informática motivou a participação e a autonomia dos acadêmicos assumindo o protagonismo na construção do seu conhecimento.

Perin e Wodewotzki (2019) discutiram o desenvolvimento da Literacia Estatística em estudantes de um curso superior tecnológico, por meio da experiência de uma atividade de Modelagem Matemática, na qual os acadêmicos puderam realizar investigações sobre temas de seus interesses. Como resultado, destacaram que o envolvimento dos acadêmicos 
com as atividades demonstrou motivação contribuindo para que compreendessem os conceitos estatísticos empregando-os com propósito nas suas pesquisas.

\section{Experiências provenientes do Ensino Médio}

Morais, Rocha e Sturion (2016) buscaram a partir de uma experiência de ensino de Estatística com estudantes do $2^{\circ}$ Ano do Ensino Médio de uma escola pública do Paraná compreender e aprimorar os saberes necessários a prática docente. Com isso, apontaram que uma prática docente fundamentada na mediação e na criticidade, pode estimular e contribuir no processo de ensino e na construção do conhecimento estatístico.

Silva e Silva (2019) investigaram as contribuições de uma sequência de ensino para o desenvolvimento do Letramento Estatístico de estudantes do $1^{\circ}$ Ano do Ensino Médio. A partir da experiência dessa sequência os autores revelaram que o ensino de Estatística precisa ser permeado por um trabalho que favoreça a capacidade crítica dos estudantes de modo que possam fazer uma leitura crítica de qualquer tipo de informação.

Musmanno et al. (2020) verificaram como uma experiência de atividade lúdica baseada no ensino de conceitos de probabilidade, por meio do jogo de dados pode contribuir no processo de aprendizagem de Estatística. Neste estudo destacaram que a compreensão e o entendimento de conceitos de Probabilidade, decorreu na medida em que os estudantes se envolviam na experiência.

\section{Experiências provenientes da Educação Infantil e dos Anos Iniciais o Ensino Fundamental}

Almeida, Fernandes e Megid (2017) relataram a experiência de um trabalho com Probabilidade e Estatística, realizado com uma turma de Educação Infantil a partir de discussões estabelecidas em um Grupo de Estudos do qual as autoras faziam parte. Nesta experiência foi percebido que a abordagem de atividades lúdicas, possibilitou um contato satisfatório entre as crianças e a Estatística, bem como criou oportunidades para que pudessem levantar hipóteses, explorar e sistematizar dados de forma diferente da usual.

Martins, Curi e Nascimento (2018) verificaram as atividades desenvolvidas por uma professora do $2^{\circ}$ Ano do Ensino Fundamental da rede estadual de São Paulo, participante do Programa Observatório da Educação, com relação aos conteúdos relativos à Estatística. 
Compreenderam que apesar das lacunas existentes na formação da professora sobre o tema, tanto os materiais disponíveis quanto as discussões coletivas partilhadas no grupo colaborativo de estudos contribuíram para seu desenvolvimento profissional.

\section{CONSIDERAÇÕES}

Com base no objetivo deste artigo, evidenciamos que apesar de selecionarmos apenas 31 estudos que atendiam aos critérios de inclusão, de um total de 1698 artigos recuperados, identificamos a existência de um crescimento de pesquisas sobre as experiências de aprendizagem e de ensino de Estatística a partir do ano 2015. Outro aspecto observado foi a influência da revista BOLEMA, bem como de edições especiais de outros periódicos que tem contribuído para publicização na área da Educação Estatística. Destacamos também o fato da Região Sudeste, em especial, as instituições de Educação Superior provenientes do estado de São Paulo, que tem se dedicado a pesquisa nesta área.

$\mathrm{Na}$ identificação dos descritores percebemos a importância do uso de termos próprios da área da Educação Estatística - Estocástica, Pensamento Estatístico, Literacia Estatística, Letramento Estatístico, Tratamento da Informação - para indicar os estudos e indexar os artigos nas plataformas eletrônicas dos periódicos.

Por meio da categorização dos artigos descrevemos investigações que versam sobre as experiências de aprendizagem e de ensino de Estatística: na Educação Infantil e Anos Iniciais voltadas a ludicidade; nos Anos Finais com enfoque no desenvolvimento do pensamento crítico, por meio da abordagem de temas transversais; no Ensino Médio associadas a sequências de ensino e jogos; na Educação Superior através do trabalho com as tecnologias digitais; nos cursos de formação de professores enfatizando a importância da participação em projetos e grupos de estudos e da partilha entre os pares. Essas investigações, em sua maioria, enfatizaram a importância da experiência de projetos de investigação, de forma que os sujeitos possam construir o seu conhecimento estatístico a partir de um tema do seu interesse, coletando, organizando, apresentando e interpretando os dados de forma crítica.

Além disso, constatamos uma predominância de investigações sobre as experiências provenientes da formação profissional para a docência, e uma limitação de estudos relativos à formação escolar anterior, principalmente, com enfoque na Educação Infantil, nos Anos 
Iniciais e no Ensino Médio, assim como, em situações do cotidiano. Contudo, entendemos a formação de professores como um processo contínuo que perdura durante toda a vida do professor, por meio de experiências que provêm de diferentes espaços e tempos. Posto isso, consideramos ser necessário investigações com abordagem nas experiências de aprendizagem e de ensino de Estatística em todos os níveis de ensino e contextos do cotidiano. A abordagem de tais investigações poderá contribuir para (re)pensarmos as experiências que tem sido (re)produzidas na aprendizagem e no ensino de Estatística, de modo a torná-las mais significativas para os estudantes e professores.

\section{AGRADECIMENTOS}

Este trabalho foi realizado com apoio da Coordenação de Aperfeiçoamento de Pessoal de Nível Superior - Brasil (CAPES) - Código de Financiamento 001.

\section{REFERÊNCIAS}

ALMEIDA; A. R. de.; FERNANDES, K. L. da S.; MEGID, M. A. B. A. Vamos ao bosque? Problematizações e Tratamento da Informação na Educação Infantil. Educação Matemática em Revista, v. 22, n. 54, p. 98-105, abr./jun. 2017.

AMÂNCIO, J. R.; VIANNA, C. C. de S.; ROCHA, N. C. dos S. Conhecimentos para a docência da probabilidade no âmbito do PIBID na UFRJ. EM TEIA: Revista de Educação Matemática e Tecnológica Iberoamericana, v. 4, n. 1, p. 1-22, 2013.

BARBOSA, G. C.; SANTOS, S. S.; LOPES; C. E. Um cenário das pesquisas em Educação Estatística no XII ENEM. REnCiMa, v. 10, n. 6, p. 319-339, dez. 2019.

BARBOSA, J. K. Formação de professores alfabetizadores para o ensino e aprendizagem da Estatística. REnCiMa, v. 9, n. 2, p. 107-126, maio 2018

BARDIN, L. Análise de Conteúdo. Lisboa: Ed. 70, 1977. 281 p.

BUENO, R. W. da S.; VIALI, L.; MÜLLER, T. J. Estudo da definição clássica de probabilidade: uma experiência com a utilização de um objeto de aprendizagem. EMRRS, n. 20, v. 1, p. 86-92, 2019.

CAMPOS, C. R. et al. Educação Estatística no contexto da Educação Crítica. Bolema, v. 24, n. 39, p. 473-494, ago. 2011.

CONCEIÇÃO, R. D. da. et al. Tratamento da Informação no Nono Ano do Ensino Fundamental: uma experiência a partir da tabela nutricional do biscoito Cream Cracker. REVEMAT, v. 14, Edição Especial Educação Estatística, p. 1-17, 2019.

COSTA, A.; NACARATO, A. M. A Estocástica na formação do professor de Matemática: percepções de professores e de formadores. Bolema, v. 24, n. 39, p. 367-386, ago. 2011. 
COSTA, W. N. G.; PAMPLONA, A. S. Entrecruzando Fronteiras: a Educação Estatística na formação de professores de Matemática. Bolema, v. 24, n. 40, p. 897-911, dez. 2011.

ESTEVAM, E. J. G.; CYRINO, M. C. de C. T. Desenvolvimento profissional de professores em Educação Estatística. JIEEM - Jornal Internacional de Estudos em Educação Matemática. v. 9, n. 1, p. 115-150, 2016.

FERREIRA, N. S. de A. As pesquisas denominadas “Estado da Arte”. Educação \& Sociedade, v. 23, n. 79, p. 257-272, ago. 2002.

FIGUEIREDO, A. de C. Ensino de Estatística: estudantes de Licenciatura em Pedagogia discutem em ambiente virtual a experiência de aplicar sequências de ensino. REVEMAT, v. 14, Edição Especial Educação Estatística, p. 1-20, 2019.

GIL, A. C. Como elaborar projetos de pesquisa. 4. ed. - São Paulo: Atlas, 2002.

JÜRGENSEN, B. D. da C. P. Um trabalho de investigação em Estatística. EMR Educação Matemática em Revista, v. 22, n. 54, p. 81-88, abr./jun. 2017.

LARROSA, J. B. Tremores: escritos sobre experiência. 1. ed. Belo Horizonte: Autêntica Editora, 2019 - Coleção Educação: Experiência e Sentido.

LEAL JUNIOR; L. C.; ONUCHIC, L. de La R.. O Jogo da imitação: A Resolução de Problemas na processualidade do ensino e da aprendizagem de Estatística e Matemática. Perspectivas da Educação Matemática INMA/UFMS, v. 11, n. 26, 2018.

LOPES, C. E. As narrativas de duas professoras em seus processos de desenvolvimento profissional em Educação Estatística. Bolema, v. 28, n. 49, p. 841-856, ago. 2014.

LOPES, C. E. Educação Estatística no curso de Licenciatura em Matemática. Bolema, v. 27, n. 47, p. 901-915, dez. 2013.

MARTINS, P. B.; CURI, E.; NASCIMENTO, J. de C. P. do. O ensino de Estatística no $2^{\circ}$ Ano do Ensino Fundamental: uma experiência em sala de aula com a construção de gráficos e tabelas. REnCiMa, v. 9, n. 2, p. 230-246, 2018.

MELO, K. M. F. de; GROENWALD, C. L. O. A Estatística articulada com o tema transversal meio ambiente: uma experiência com alunos dos Anos Finais do Ensino Fundamental. REVEMAT, v. 9, n. 2, p. 1-22, 2014.

MELO, K. M. F. de; GROENWALD, C. L. O. O pensamento Estatístico no Ensino Fundamental: uma experiência com projetos de pesquisa articulados com uma sequência didática eletrônica. REnCiMa, v. 9, n. 2, p. 300-319, 2018.

MELO, K. M. F. de; GROENWALD, C. L. O. Testes adaptativos e os níveis distintos de compreensão para tabelas e gráficos: uma experiência com alunos dos Anos Finais do Ensino Fundamental. REMATEC, v. 10, n. 19, p. 59-78, maio/ago. 2015.

MORAIS, D. A. M.; ROCHA, Z. de F. D. C.; STURION, L. Interação conteúdo e prática: uma contribuição para o ensino de Estatística. Amazônia: Revista de Educação em

Ciências e Matemática, v. 13, n. 25, p. 21-32, jul./dez. 2016. 
MOROSINI; M. C. Estado de Conhecimento e questões do campo científico. Educação, v. 40, n. 1, p. 101-116, jan./abr. 2015.

MOROSINI; M. C.; FERNANDES, C. M. B. Estado do Conhecimento: conceitos, finalidades e interlocuções. Educação Por Escrito, v. 5, n. 2, p. 154-164, jul./dez. 2014.

MUSMANNO, L. et al. Relato de Experiência: probabilidade no Ensino Médio. Educação Matemática em Revista, v. 25, n. 66, p.239-251, jan./mar. 2020.

OLIVEIRA JÚNIOR, A. P. de. Reflexão sobre as características sócio demográficas, educacionais, do uso de tecnologias e das práticas docentes de professores de Estatística no Ensino Superior no Brasil. Bolema, v. 24, n. 39, p. 387-412, ago. 2011.

OLIVEIRA JÚNIOR, A. P. de; ANJOS, R. de C. dos; SILVA, J. dos S. O ensino de conceitos estatísticos por meio de projetos na formação de professores de Matemática.

Caminhos da Educação Matemática em Revista, v. 9, n. 2, p. 63-78, 2019.

OLIVEIRA JÚNIOR, A. P. de; FERNANDES, J. A. A investigação e a tecnologia da informação no ensino de Estatística. EM TEIA: Revista de Educação Matemática e Tecnológica Iberoamericana, v. 4 n. 1, p. 1-21, 2013

PAMPLONA, A. S.; CARVALHO, D. L. de. A Educação Estatística e as relações de poder em comunidades de prática. Bolema, v. 24, n. 39, p. 351-366, ago. 2011.

PERIN, A. P.; WODEWOTZKI, M. L. L. A modelagem Matemática: um ambiente para o desenvolvimento do raciocínio estatístico. Caminhos da Educação Matemática em Revista, v. 9, n. 2, p. 158-170, 2019.

ROMANOWSKI, J. P.; ENS, R. T. As pesquisas denominadas do tipo "Estado da Arte" em educação. Diálogo Educação, v. 6, n.19, p.37-50, set./dez. 2006.

SAMÁ, S. Caminhos Trilhados pelo GT12 nas pesquisas em Educação Estatística no Brasil, no Período de 2016 a 2018. REVEMAT, v. 14, Edição Especial Educação Estatística, p. 1-18, 2019.

SANTANA; M. L. de. et al. O acompanhamento de coordenadores pedagógicos por formadores em Matemática: uma experiência com Tratamento da Informação.

REVEMAT, v. 12, n. 2, p. 274-291, 2017.

SCARLASSARI, N. T.; SOCHA, R. R.; LOPES, C. E. A contribuição da Educação Estatística para a conscientização de uma alimentação saudável. EMR- Educação Matemática em Revista, v. 23, n. 59, p. 126-138, jul./set. 2018.

SILVA, C. B. da. Cinco anos de evolução das pesquisas em Educação Estatística: uma análise da produção científica dos pesquisadores do GT-12. In: III Fórum de discussão: parâmetros balizadores da pesquisa em Educação Matemática, 2015, São Paulo. (Anais) p. 1-17. Disponível em: $<$ https://www.pucsp.br/IIIpesquisaedmat/download/resumos/

GD9-paper-forum-Claudia-Borim.pdf>. Acesso em: 10 de novembro de 2020.

SILVA, C. R.; PORCIÚNCULA M. Atos de Insubordinação Criativa experienciados no aprender e no ensinar a Estatística. RIPEM, v. 10, n.1, p. 137-15, 2020. 
SILVA, D. de J. Caixa estatística: otimizando o estudo de amostragem e estimação. Revista de Educação, Ciências e Matemática v. 9 n. 3. p. 223 - 234, set./dez. 2019.

SILVA, E. I. da; SILVA, J. P. da. Letramento Estatístico: uma experiência no $1^{\circ}$ Ano do Ensino Médio. Caminhos da Educação Matemática em Revista, v. 9, n. 2, p. 171-186, 2019.

SILVA, J. F.; CURI, E.; SCHIMIGUEL, J. Um Cenário sobre a Pesquisa em Educação Estatística no Boletim de Educação Matemática - BOLEMA, de 2006 até 2015. Bolema, v. 31, n. 58, p. 679-698, ago. 2017.

SOUZA JUNIOR, A. J. de; CAMPOS, S. G.V. B. Trabalho de projetos no processo de ensinar e aprender Estatística na Universidade. Bolema, v. 24, n. 39, p. 413-429, ago. 2011.

TARDIF, M. Saberes docentes e formação profissional. 17. ed. Petrópolis: Vozes 2014.

Submetido em 12 de novembro de 2020. Aprovado em 15 de janeiro de 2021. 